\title{
Solubility Parameter and Random-Coil Dimensions of Poly(1,3-Dioxolane)
}

\author{
Rufina Alamo, José G. Fatou, and Antonio Bello \\ Sección de Física y Fisicoquìmica de Polímeros, \\ Instituto de Plásticos y Caucho, C.S.I.C., \\ Juan de la Cierva, 3, Madrid-6, Spain
}

(Received September 7, 1982)

\begin{abstract}
Intrinsic viscosity measurements and turbidimetric titrations were made on a polydioxolane sample in a series of solvents to determine the solubility parameter. The FloryHuggins interaction parameter was also used for the same purpose. The assigned solubility parameter, $\partial=10.1 \mathrm{cal}^{1 / 2} \mathrm{~cm}^{-3 / 2}$, agrees well with the calculated from the attraction molar constants. Dilute solution properties were determined from osmometric and viscometric measurements on fractions of polydioxolane in tetrahydrofuran at $25^{\circ} \mathrm{C}$. The data were interrelated and analyzed by the Orofino-Flory equation and a value found for the characteristic ratio $\left\langle\bar{r}^{2}\right\rangle_{0} / n l^{2}$ of 3.72 agreed quite well with the previously reported theoretical value.

KEY WORDS Poly(1,3-dioxolane) / Solubility Parameter / Cohesive Energy Density / Interaction Coefficient / Characteristic Ratio /
\end{abstract}

Polyformals with the general formula $\mathrm{tO}_{-}$ $\mathrm{CH}_{2}-\mathrm{O}-\left(\mathrm{CH}_{2}\right)_{n}$ + $_{m}$ are the alternating copolymers of formaldehyde and $\alpha, \omega$-glycols.

The properties of these polymers depend on the number of methylene groups in the repeat unit. The first member, polyoxymethylene $(n=1)$ has been investigated to some extent in solution ${ }^{1}$ and in bulk. ${ }^{2,3}$ The second member of the polyformal series is poly(1,3-dioxolane) (PDOL).

In previous papers, ${ }^{4-6}$ we investigated the polymerization mechanism and the crystallization kinetics of this polymer. Among the main factors affecting the physical properties of polymeric materials are the cohesive energy and the chain flexibility. An approximate knowledge of the magnitude of these two factors can be obtained from a study of solution properties. From an experimental point of view, such physical properties of PDOL as its relatively low melting temperature and solubility in numerous organic solvents facilitate an understanding of the properties of this polymer.

In order to describe the solubility behaviour of PDOL a useful parameter is the solubility parameter, $\partial$, from which, for non-polar and moderately polar systems the order of magnitude of the solutesolvent interaction parameter, $\chi$, can be estimated.
Moreover, the solubility parameter is related to the cohesive energy density which gives some information about the value of intermolecular forces in a polymer in the amorphous state. An important property is the chain flexibility which depends on the facility with which the backbone chain bonds can rotate. A measure of the hindrance to rotation is given by the characteristic ratio $\left\langle\bar{r}^{2}\right\rangle_{0} / n l^{2}$ which represents the factor by which the actual unperturbed dimensions of the chain differ from those the chain would have if it were freely jointed. There are some estimates of this characteristic ratio for PDOL $^{7,8}$ and also values calculated on the basis of the rotational isomeric state theory have been reported..$^{9,10}$ In order to obtain information on the intermolecular forces and flexibility in poly $(1,3-$ dioxolane) we attempted to evaluate the solubility parameter by a variety of methods and the characteristic ratio from viscometric and osmometric data.

\section{EXPERIMENTAL}

\section{Materials}

Poly(1,3-dioxolane) was prepared by solution polymerization of 1,3-dioxolane in methylene chloride at $0^{\circ} \mathrm{C}$, using acetyl perchlorate as an initiator. ${ }^{4}$ The 
polymer was precipitated in hexane, dried in vacuum, and purified by dissolving it in benzene and further liophilization.

The whole polymer was fractionated at $25^{\circ} \mathrm{C}$ in the system $n$-hexane-ethanol-benzene mixtures.

\section{Molecular Weights}

Number-average molecular weights $M_{n}$ were measured in a Mechrolab high-speed membrane osmometer model 502 equiped with a variable temperature controller. The membranes used were ultracellafilter grade finest, and were conditioned from 1-propanol to tetrahydrofuran (THF). The data were obtained at $25^{\circ} \mathrm{C}$ in THF, measurements were made at four or five different concentrations and the results were analyzed according to the equation:

$$
\frac{\pi}{c}=\frac{R T}{M_{n}}+A_{2} C+\cdots
$$

where $\pi$ is the osmotic pressure, $A_{2}$ the second virial coefficient, and $R T$ has the usual meaning. Four fractions were measured in the range from 35500 to 110000.

Light scattering measurements were carried out at $25^{\circ} \mathrm{C}$ in a Sofica automatic light scattering photometer (model 4200) over an angular range from 30 to $150^{\circ}$. Light of wavelength $546 \mathrm{~nm}$ was used as the incident beam. Measurements were carried out on the fraction $M_{n}=110000$, with solutions of polymer concentration ranging from 10.36 to $2.30 \mathrm{~g}^{-1}$ in chlorobenzene. Just before measurement each solution was filtered directly into the light-scattering cell, through a Millipore filter $(100 \mathrm{~nm})$ for optical purification.

The specific refractive index increments of the polymer solutions were determined by a BricePhoenix differential refractometer using light of wavelenght $546 \mathrm{~nm}(\mathrm{~d} n / \mathrm{d} c=0.05)$.

\section{Viscosity}

Viscosity measurements were made at $25 \pm 0.01^{\circ} \mathrm{C}$ using a capillary viscometer of the Ubbelhode type. Neither the kinetic-energy correction nor the non-Newtonian correction were found to be necessary. The fraction used for solubility parameter measurements had a number-molecular weight of 90000. The solvents used are listed in Table I.

The intrinsic viscosity, [ $\eta]$, was determined by extrapolating two types of viscosity-concentration plots, i.e., $\eta_{\mathrm{sp}} / c$ and $\left(\ln \eta_{\mathrm{r}}\right) / c$ vs. $c$ so as to yield a common intercept at $c=0$.

\section{Turbidimetry}

Turbidimetric measurements were carried out at $25^{\circ} \mathrm{C}$ in a Spekker apparatus on solutions with concentrations of $0.2 \mathrm{~g} \mathrm{dl}^{-1}$ in the solvents listed in Table I. To the solution $(15 \mathrm{ml})$, a non-solvent was slowly added until a cloud point was reached. Two non-solvents, having high (ethanol) and low ( $n$ hexane) solubility parameters respectively were used for the turbidimetric titrations.

\section{RESULTS AND DISCUSSION}

\section{Solubility Parameter of $P D O L$}

The solubility parameter, $\partial$, has been used for predicting the "compatibility" or phase behavior of solvent and polymer. This scheme is based on the regular solution theory of Hildebrand and others ${ }^{11}$ and assumes that phase behavior is determined by two factors: a combinatorial entropy term which depends only on the volume fraction of each component in the phase and an energy term which depends on the difference between like and unlike interactions. The last factor is associated with changes in the nearest neighbour contacts during mixing and is given by the relationship $E_{\mathrm{m}}=$ $V_{\mathrm{m}} \phi_{\mathrm{s}} \phi_{\mathrm{p}}\left(\partial_{\mathrm{s}}-\partial_{\mathrm{p}}\right)^{2}$, where $V_{\mathrm{m}}$ is the total volume of the mixture, the $\Phi$ the volume fractions of the two components and $E_{\mathrm{m}}$, the internal energy or enthalpy of mixing. Since the assumed theory disregards changes in volume on solution, both magnitudes are equal.

Also, the theory of regular solutions does not consider any specific interaction between both components, so the maximum interaction corresponds to $E_{\mathrm{m}} \rightarrow 0$ and $\partial_{\mathrm{s}}=\partial_{\mathrm{p}}$. From this fact it is possible to determine the solubility parameter of polymers. Swelling of crosslinked polymers and viscosities have been extensively used to determine the maximum interaction of polymer-solvents, and from this the solubility parameter of a polymer can be obtained.

The results of this last method applied to the PDOL are given in Figure 1, where $[\eta]$ is plotted against the solubility parameter, $\partial_{\mathrm{s}}$ of the solvents listed in Table I. Through the experimental points, it was possible to draw a smooth curve whose maximum corresponds to a value of $\partial_{\mathrm{p}}=9.8 \mathrm{cal}^{1 / 2}$ $\mathrm{cm}^{-3 / 2}\left(20 \mathrm{~J}^{1 / 2} \mathrm{~cm}^{-3 / 2}\right)$. On the assumption that the 


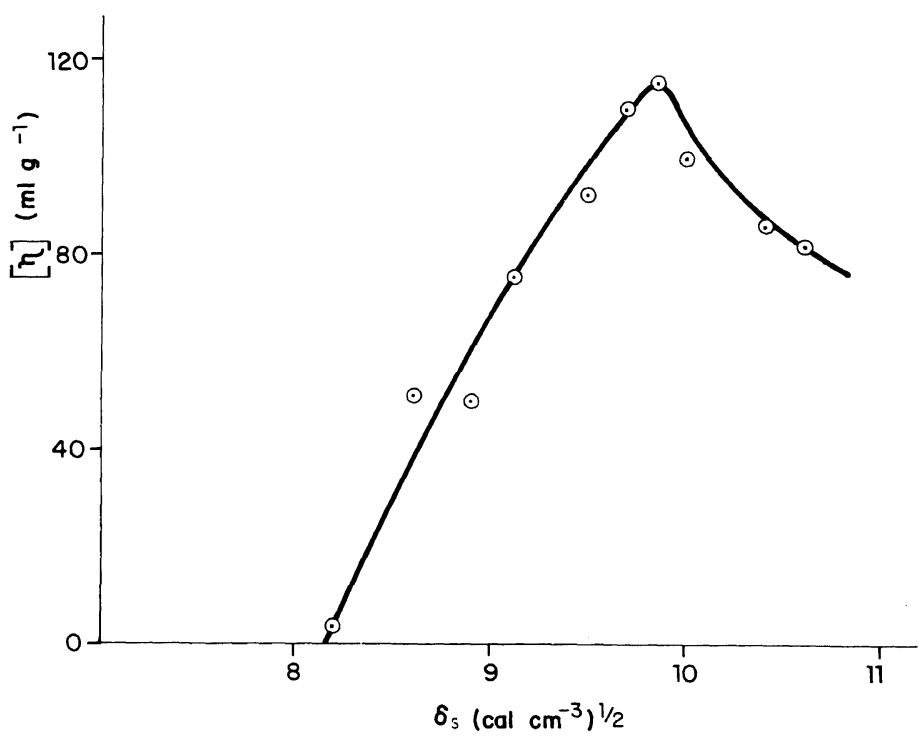

Figure 1. Intrinsic viscosity vs. solubility parameter of the solvent.

Table I. Viscometric and turbidimetric results

\begin{tabular}{|c|c|c|c|c|}
\hline & $\delta_{s}$ & $V_{1}$ & {$[\eta]$} & $\delta_{3}$ \\
\hline & $\left(\mathrm{cal} \mathrm{cm}^{-3}\right)^{1 / 2}$ & $\mathrm{cal}^{3} \mathrm{~mol}^{-1}$ & $\mathrm{~cm}^{3} \mathrm{~g}^{-1}$ & $\left(\mathrm{calcm}^{-3}\right)^{1 / 2}$ \\
\hline \multicolumn{5}{|l|}{ Solvents } \\
\hline Ethyl benzoate & 8.2 & 143.6 & 3.5 & 9.65 \\
\hline Carbon tetrachloride & 8.6 & 96.5 & 51 & - \\
\hline Toluene & 8.9 & 106.3 & 50 & 9.50 \\
\hline Tetrahydrofuran & 9.1 & 81.1 & 75 & 9.66 \\
\hline Chlorobenzene & 9.5 & 101.7 & 87 & - \\
\hline Tetrachloroethane & 9.7 & 105.0 & 110 & 9.92 \\
\hline Ethylene dichloride & 9.85 & 78.8 & 115 & 10.17 \\
\hline 1,4 Dioxane & 10.0 & 85.3 & 100 & 10.26 \\
\hline Cyclopentanone & 10.4 & 88.5 & 86 & - \\
\hline Acetophenone & 10.6 & 116.9 & 82 & 10.41 \\
\hline \multicolumn{5}{|l|}{ Non-solvents } \\
\hline Ethanol & 12.8 & 78.6 & - & - \\
\hline$n$-Hexane & 7.3 & 130.6 & - & - \\
\hline
\end{tabular}

equation, $[\eta]=[\eta]_{\max } \exp -K V\left(\partial_{s}-\partial_{\mathrm{p}}\right)^{2}$ where $V$ is the molar volume of the solvent, the point of intersection of the line with the abscisa gives $\partial_{p}=9.9$ $\mathrm{cal}^{1 / 2} \mathrm{~cm}^{-3 / 2}\left(20.0 \mathrm{~J}^{1 / 2} \mathrm{~cm}^{-3 / 2}\right)$ (Figure 2).

The solubility parameter was also obtained from the polymer-solvent interaction parameter, $\chi$. According to the Flory-Huggins theory ${ }^{12}$ the partial molar free energy of dilution is given by

$$
\Delta F_{1}=R T\left[\ln \left(1-V_{2}\right)+\left(1-\frac{1}{X}\right) V^{2}+\chi V_{2}^{2}\right]
$$

where $V_{2}$ is the volume fraction of the polymer, $\chi$ is the ratio of the molar volumes of the polymer and solvent and $\chi$ is the interaction parameter. To the extent that this formulation is adequate, the value of $\chi$ may possibly be related to the osmotic second 


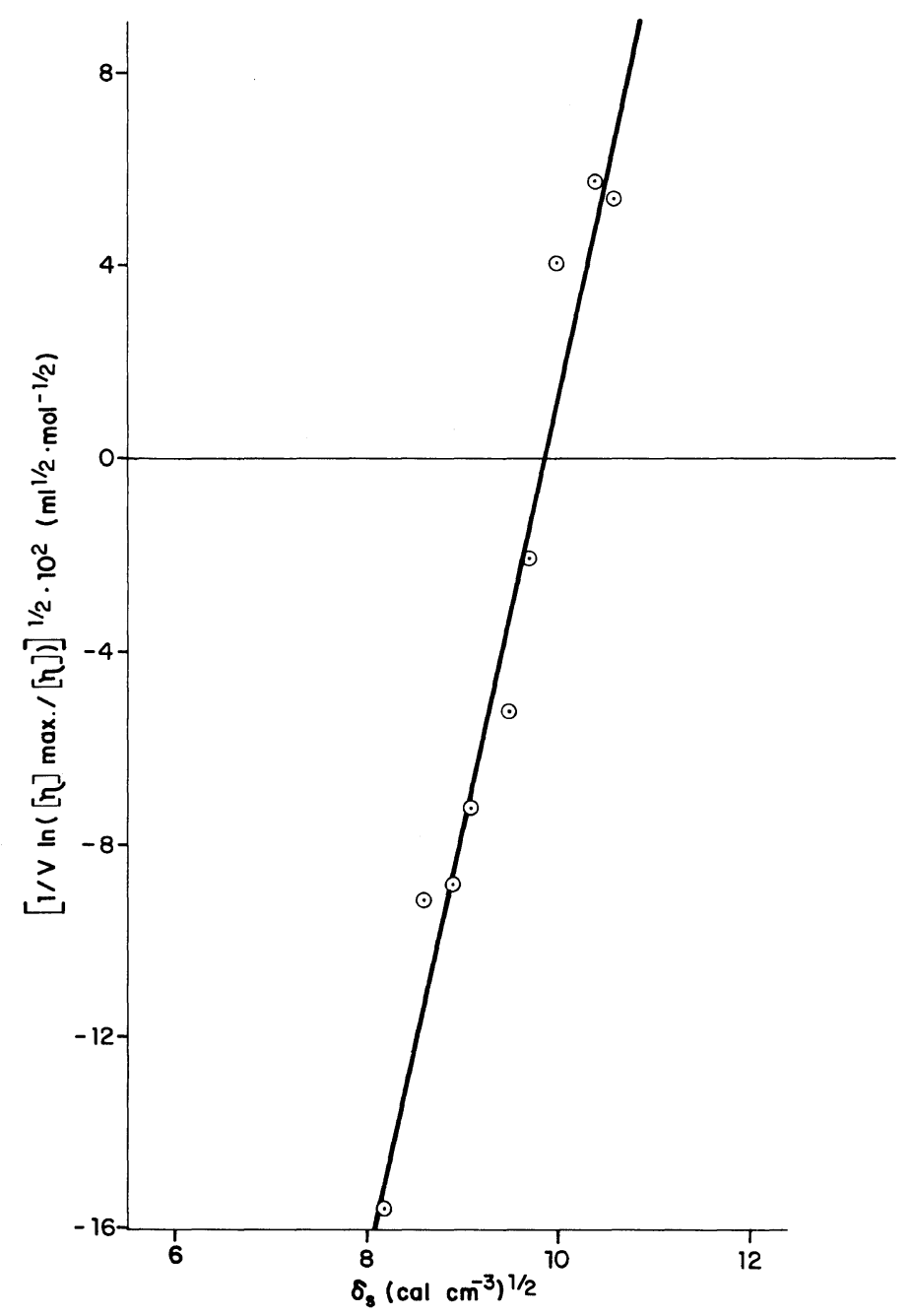

Figure 2. Calculation of $\delta_{\mathrm{p}}$ from viscosity by the intercept method.

virial coefficient, $A_{2}$, by the following equation

$$
A_{2}=\frac{\bar{V}_{2}}{M V}\left(\frac{1}{2}-\chi\right)
$$

where $\bar{V}_{2}$ is the molar volume of the polymer and $M$ the molecular weight.

To minimize the effect of neglecting higher interaction terms in evaluating the primary parameter, $\chi$, from virial coefficients, only the higher fraction of $M_{n}=110000$ was considered, and for this fraction a value of $\chi=0.377$ was deduced from eq 3 . By the equation ${ }^{13}$

$$
\chi=\frac{1}{2}+\frac{V\left(\partial_{\mathrm{s}}-\partial_{\mathrm{p}}\right)^{2}}{R T}
$$

assuming a value of $1 / 3$ for the reciprocal of the lattice number and taking the solubility parameter for THF to be $9.1 \mathrm{cal}^{1 / 2} \mathrm{~cm}^{-3 / 2}$, the solubility parameter of the polymer was estimated to be 9.6 $\mathrm{cal}^{1 / 2} \mathrm{~cm}^{-3} / 2$, which is close to the value obtained from intrinsic viscosities.

The solubility parameter was determined also by turbidimetric titrations according to the method developed by Such and Clarke. ${ }^{14}$ If $\partial_{\mathrm{m}}$ is defined as the solubility parameter of solvent/non-solvent mix- 
tures, at the cloud points the values of the FloryHuggins interaction parameter, $\chi$, given by eq 4 are equal. Such and Clarke obtained the relationship for the solubility parameter of the polymer:

$$
\partial_{3}=\left(V_{\mathrm{ml}}^{1 / 2} \partial_{\mathrm{m} 1}+V_{\mathrm{mh}}^{1 / 2} \partial_{\mathrm{mh}}\right) /\left(V_{\mathrm{m} 1}^{1 / 2}+V_{\mathrm{mh}}^{1 / 2}\right)
$$

where subscripts $\mathrm{mh}$ and $\mathrm{ml}$ indicate mixtures of a solvent with a non-solvent of high or low solubility parameter. Values of $\partial_{\mathrm{m}}$ and $V_{\mathrm{m}}$ may be calculated from the expressions ${ }^{15}$

$$
\begin{aligned}
& \partial_{\mathrm{m}}=\Phi_{1} \partial_{1}+\Phi_{2} \partial_{2} \\
& V_{\mathrm{m}}=V_{1} V_{2} /\left(\Phi_{1} V_{2}+\Phi_{2} V_{1}\right)
\end{aligned}
$$

where the subscripts 1 and 2 refer to the solvent and non-solvent and $\Phi$ and $V$ are the volume fraction and the molar volume, respectively. Values of $\partial_{3}$, calculated from eq 5 yield almost a vertical line as shown in Figure 3. The solubility parameter was determined as the point of intersection of the straight line expressing the dependence of $\partial_{1}$ on $\partial_{3}$ eq 6 with the line $\partial_{3}=\partial_{1}$. The value of $\partial_{\mathrm{p}}$ is 10.3 $\mathrm{cal}^{1 / 2} \mathrm{~cm}^{-3 / 2}\left(21.1 \mathrm{~J}^{1 / 2} \mathrm{~cm}^{-3 / 2}\right)$, which is slightly higher than the one obtained from viscosity measurements.

Another method for estimating solubility parameter has been described and is based on the assumption that cohesive energies are additive. Small ${ }^{16}$ proposed the relationship

$$
\partial_{\mathrm{p}}=\frac{\rho \Sigma F}{M_{0}}
$$

where $F$ is the group attraction constant, $M_{0}$ is the molecular weight of the repeating unit and $\rho$ is the density of the polymer.

For the $\sum F$ values, there are two sets of tabulated data, one by Small ${ }^{16}$ and another by Hoy. ${ }^{17}$ Both give the same molar attraction constants for the $\mathrm{CH}_{2}$ group, but not for the ether group.

The density of the amorphous PDOL at $25^{\circ} \mathrm{C}$ is $1.29 \mathrm{~g} \mathrm{~cm}^{-318}$ and, so, the calculated $\partial_{\mathrm{p}}$ from Small's and Hoy's tables are 9.4 and $10.9 \mathrm{cal}^{1 / 2}$ $\mathrm{cm}^{-3 / 2}$, respectively.

The cohesive energy density can be calculated assuming that $\operatorname{CED}=\left(\partial_{\mathrm{p}}\right)^{2}$. Table II shows $\partial$ and CED values obtained by different methods of analysis. The average value of the solubility parameter of PDOL from the experimental results is $\partial_{p}=10.1$ $\mathrm{cal}^{1 / 2} \mathrm{~cm}^{-3 / 2}\left(20.6 \mathrm{~J}^{1 / 2} \mathrm{~cm}^{-3 / 2}\right)$.

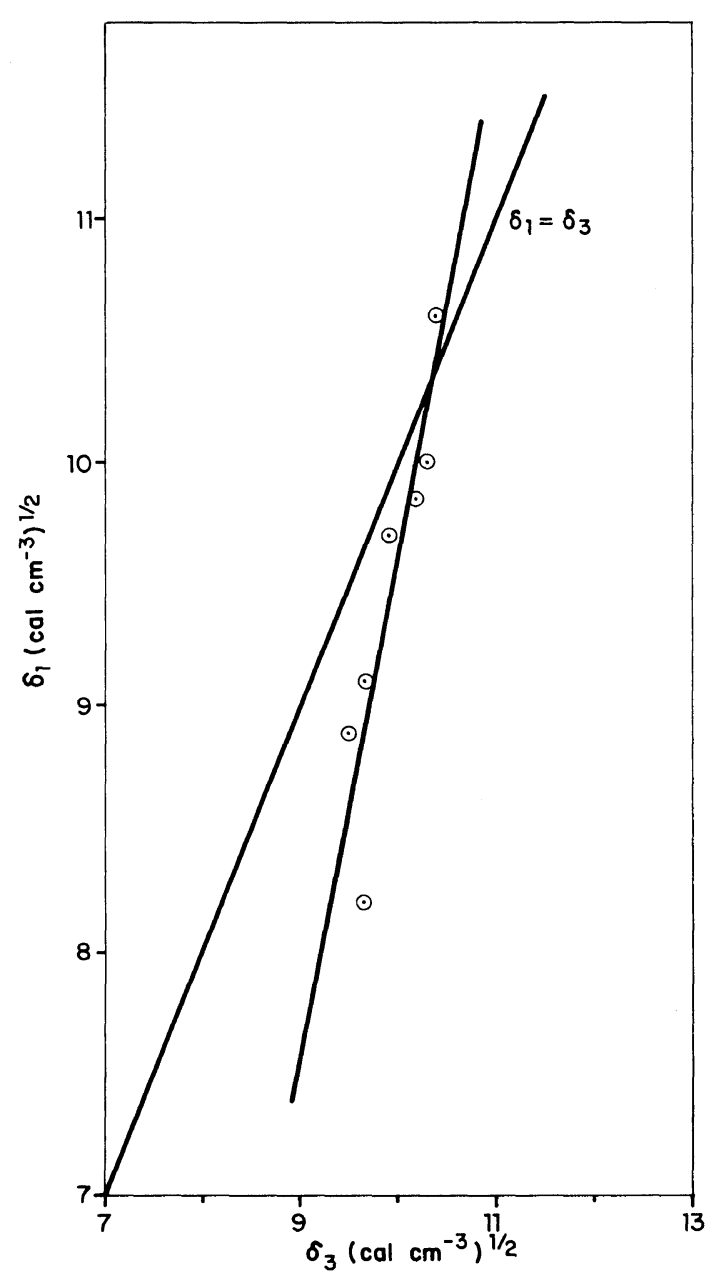

Figure 3. Solubility parameter of PDOL from turbidimetric titration method.

Table II. Solubility parameters

\begin{tabular}{lrrr}
\hline \multirow{1}{*}{ Method } & \multicolumn{1}{c}{$\delta$} & & \multicolumn{1}{c}{ CED } \\
\cline { 2 - 2 } & $\left(\mathrm{cal} \mathrm{cm}^{-3}\right)^{1 / 2}$ & & $\mathrm{cal} \mathrm{cm}^{-3}$ \\
\hline Viscosity & 9.9 & & 98.0 \\
Turbidimetric & 10.3 & & 106.1 \\
Interaction coefficient & 9.6 & & 92.2 \\
Attraction molar constants & & \\
$\quad$ Small & 9.4 & & 88.4 \\
$\quad$ Hoy & 10.9 & & 118.8 \\
\hline
\end{tabular}




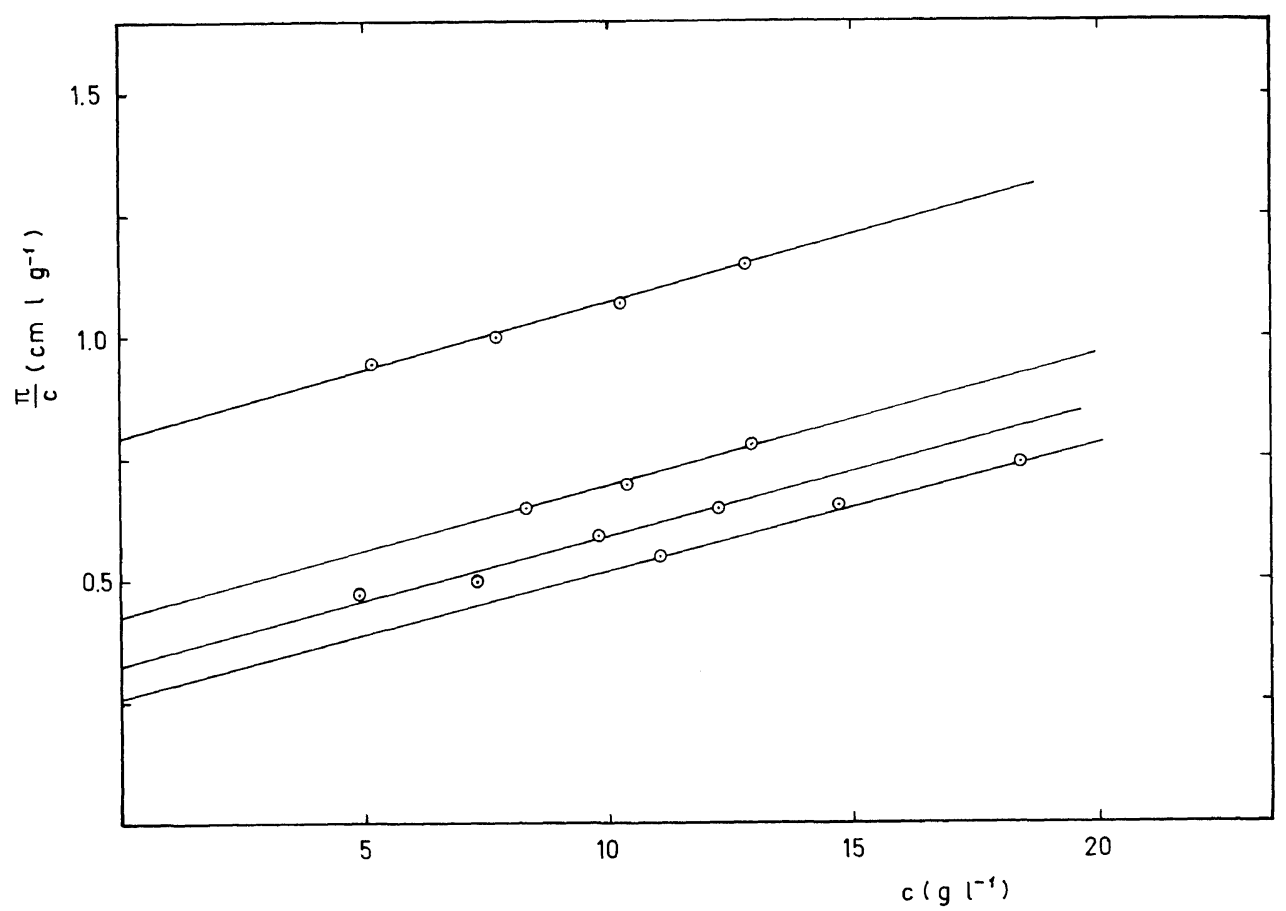

Figure 4. Osmometric data obtained on PDOL fractions in THF at $25^{\circ} \mathrm{C}$.

Table III. Viscometric and osmometric results in THF at $25^{\circ} \mathrm{C}$

\begin{tabular}{cccccccc}
\hline Fraction & $M_{n} \times 10^{-4}$ & $M_{w} \times 10^{-4}$ & $\frac{[\eta]}{\mathrm{dlg}^{-1}}$ & $\frac{A_{2} \times 10^{3}}{\mathrm{~cm}^{3} \mathrm{~mol}^{-1} \mathrm{~g}^{-2}}$ & & $\alpha^{\mathrm{a}}$ & \\
\hline PDOL-1 & 11.0 & 13.5 & 0.822 & $0.915(1.096)^{\mathrm{b}}$ & 1.424 & 3.77 \\
PDOL-2 & 9.0 & & 0.702 & 0.940 & 1.418 & 3.76 \\
PDOL-3 & 6.6 & & 0.540 & 0.948 & 1.398 & 3.61 \\
PDOL-4 & 3.55 & & 0.360 & 0.978 & 1.323 & 3.77 \\
\hline
\end{tabular}

a Is the expansion chain factor.

b In chlorobenzene at $25^{\circ} \mathrm{C}$.

\section{Characteristic Ratio of PDOL}

The results of osmotic pressure measurements on four fractions of PDOL in THF at $25^{\circ} \mathrm{C}$ are shown in Figure 4. The relation between $\pi / c$ and $c$ for each fraction is represented by a straight line.

The value of $A_{2}$ was calculated from the slope of the straight line according to eq 1 (Table III). It can be seen that the values of $A_{2}$ follow the general trend and $A_{2}$ decreases as the molecular weight increases, fitting the equation: $A_{2}=C M^{-\varepsilon}$ with $\varepsilon$ in the region $0.05-0.06$.
The Houwink-Mark-Sakurada equation, $[\eta]=$ $K \bar{M}^{\alpha}$ for $\mathrm{PDOL}^{19}$ has been reported previously, but was determined using unfractionated samples. The method used for the synthesis was a cationic ring opening polymerization of dioxolane with triethyloxonium tetrafluoroborate, which due to the presence of transfer reactions, gives samples broad in molecular weight distribution. The presence of cyclic molecules along those that are linear cannot be ruled out. ${ }^{19}$

The data points in Figure 5 are fitted reasonably 


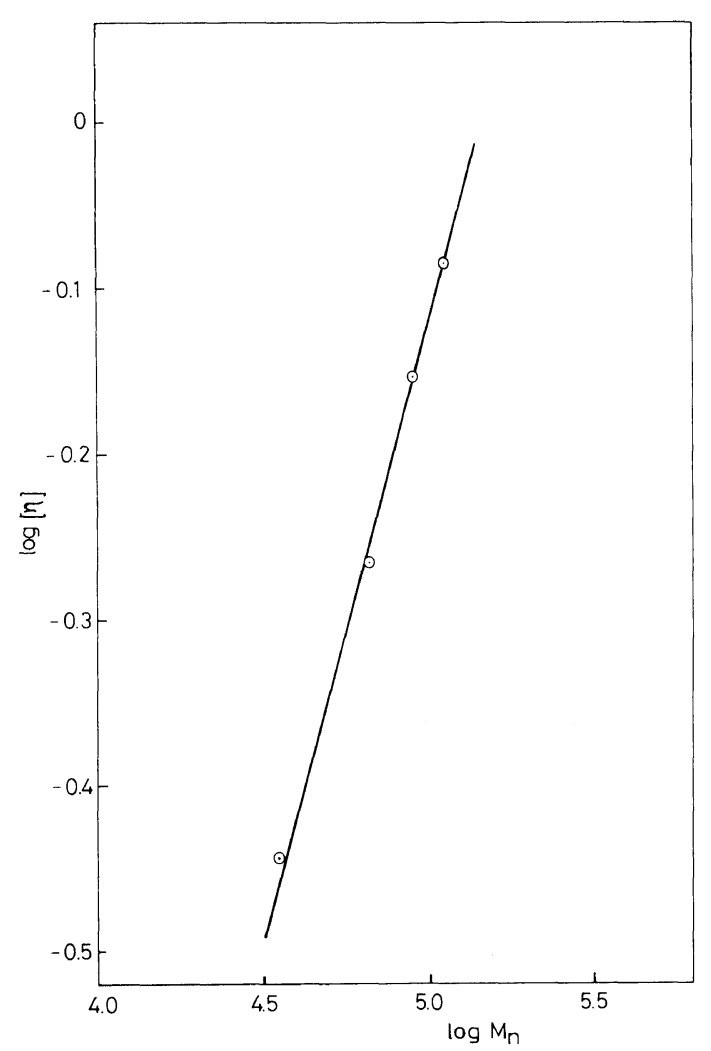

Figure 5. The intrinsic viscosity molecular weight relationship for PDOL in THF at $25^{\circ} \mathrm{C}$.

well by a straight line over the range of $35500<M_{n}<110000$, and give the following H-M$\mathrm{S}$ relation for poly(1,3-dioxolane) in tetrahydrofuran at $25^{\circ} \mathrm{C}$.

$$
[\eta]=1.7 \times 10^{-4} M_{n}^{0.73}
$$

where $[\eta]$ is expressed in $\mathrm{dl} \mathrm{g}^{-1}$.

Since this relationship is expressed in terms of $M_{n}$, the value of $K$ should be sensitively dependent on the molecular weight distributions of the samples. Polydioxolane is relatively easily degraded through the acetals groups. In order to determine the molecular weight distribution, light scattering measurements of $M_{w}$ for one fraction of PDOL were made using Zimm's method of double extrapolation. The results in chlorobenzene at $25^{\circ} \mathrm{C}$ given in Table III show that for sample PDOL-1, the second virial coefficient is higher in chlorobenzene than in THF. This agrees with the higher intrinsic viscosity found in the measurement of the solubility parameter. The
$M_{w} / M_{n} \simeq 1.2$ for this fraction represents a relatively narrow molecular weight distribution.

If it is assumed that this value of $M_{w} / M_{n}$ holds for the other three fractions and also that the molecular weight distribution of each fraction can be expressed by Schulz-Zimm's exponential function, the value of $K$ for an ideal monodisperse sample should decrease from $1.7 \times 10^{-4}$ in eq 8 to $1.5 \times 10^{-4}$.

The intrinsic viscosities and osmometric data were used to deduce the coil dimensions for PDOL. In order to characterize its spatial extension, a convenient parameter is the unperturbed mean square end-to-end distance from which the conformation factor can be calculated and this valuable information concerning to the structure of the PDOL is obtained. To deduce this parameter from measurements in good solvents the expansion coefficient $\alpha=\left\langle\vec{r}^{2}\right\rangle^{1 / 2} /\left\langle r^{2}\right\rangle_{0}^{1 / 2}$ must be determined.

This was done using the values of $A_{2},[\eta]$, and $M_{n}$, given in Table III, and the relation of Orofino and Flory

$$
\begin{aligned}
& \ln \left[1+\left(\pi^{1 / 2} / 2\right)\left(\alpha^{2}-1\right)\right] \\
= & \left(27 \Phi / 2^{5 / 2} \pi N_{\mathrm{A}}\right)\left(A_{2} M_{n} /[\eta]\right)
\end{aligned}
$$

where $N_{\mathrm{A}}$ is the Avogadro constant and $\Phi$ Flory's parameter for which a value of $2.1 \times 10^{21} \mathrm{dl} \mathrm{cm}^{-3}$ $\mathrm{mol}^{-1}$ was used. ${ }^{21}$ The values of $\alpha$ are included in Table III and from these, $\left\langle\vec{r}^{2}\right\rangle_{0}$ was calcualted using the relationship $[\eta]=\Phi\left[\left\langle\bar{r}^{2}\right\rangle_{0} / M_{n}\right]^{3 / 2} M_{n}{ }^{1 / 2} \alpha^{3}$.

The characteristic ratio $\left\langle\bar{r}^{2}\right\rangle_{0} / n l^{2}$ was calculated from the values of $\left\langle\vec{r}^{2}\right\rangle_{0}, n$, the number of the bonds equal to $5 M_{n} / M_{0}$ and $l^{2}$, average of the squares of the bond lenghts,

$$
l_{\mathrm{C}-\mathrm{C}}=1.555 \AA \text { and } l_{\mathrm{C}-\mathrm{O}}=1.43 \AA .
$$

The resulting value of the characteristic ratio for PDOL was 3.72. This value indicates that PDOL is a very compact chain molecule and that the degree of hindrance to internal rotation is slight. Compare to the polymethylene chain, the substitution of oxigens by methylene groups, from the stand point of the spatial extension of the molecule exerts two main effects: a shortening of the bonds and the removal of two hydrogen atoms to decrease the pentane effect, i.e., the $\mathrm{GG}^{\prime}$ or $\mathrm{G}^{\prime} \mathrm{G}$ conformation may not be totally prohibited. Hence when the interacting groups separated by four bonds are $\mathrm{CH}_{2}$ and $\mathrm{O}$ atoms, these conformations are partially allowed, ${ }^{9}$ while almost completely excluded when the two groups are $\mathrm{CH}_{2}$, 
Approximate experimental values for the characteristic ratio for PDOL have been previously reported. Using low molecular weight samples and the equation of Stockmayer and Fixman, ${ }^{22}$ a value of 3.9 was obtained by Gorin. ${ }^{7}$

This ratio also has been theoretically calculated, using the rotational isomeric state theory. A value of 4.4 at $60^{\circ} \mathrm{C}$ was obtained early by Semlyen, ${ }^{8}$ and more recently Riande, et $a .^{10}$ derived a value of 3.69 at $25^{\circ} \mathrm{C}$. The agreement between experimental and theoretical values is quite good, and although the spatial extension of this molecule may be less sensitive to conformational changes than some other configurational-dependent properties, this result gives some support to the energy parameters used in the rotational isomeric state calculations.

Acknowledgements. We should like to express our sincere appreciation for the capable assistance of Mr. M. G. Rodriguez in making the viscometric and turbidimetric measurements. The financial support of the Comisión Asesora de Investigación Científica y Técnica is gratefully acknowledged.

\section{REFERENCES}

1. W. H. Stockmayer and L. Chan, J. Polym. Sci. A-2, 4, 437 (1966).

2. Z. Pelzbauer and A. Galeski, J. Polym. Sci., C, 38, 23 (1972).

3. M. Mihajlov and E. Nedkov, J. Polym. Sci., C, 38, 33 (1972).

4. R. Alamo, J. Guzmán, and J. G. Fatou, An. Quim.,
78, 317 (1982).

5. R. Alamo, J. G. Fatou, and J. Guzmán, Polymer, 23, 374 (1982).

6. R. Alamo, J. G. Fatou and J. Guzmán, Polymer, 23, 379 (1982).

7. S. Gorin and L. Monnerie, J. Chim. Phys. Phys.Chim. Biol., 65, 2084 (1968).

8. J. M. Andrews and J. A. Semlyen, Polymer, 13, 142 (1972).

9. E. Riande and J. E. Mark, Macromolecules, 11, 956 (1978).

10. E. Riande, E. Saiz, and J. E. Mark, Macromolecules, 13, 448 (1980).

11. J. H. Hildebrand, R. L. Scott, "The Solubility of Nonelectrolytes," 3rd ed, Reinhold Publishing Corp. New York, 1950.

12. P. J. Flory, "Principles of Polymer Chemistry," Cornell University Press, Ithaca, N. Y., 1953.

13. R. L. Scott and M. Magat, J. Polym. Sci., 4, 555 (1949).

14. K: W. Suh and D. H. Clarke, J. Polym. Sci., A-1, 5, 1671 (1967).

15. R. L. Scott, J. Chem. Phys., 17, 268 (1949).

16. P. A. Small, J. Appl. Chem., 3, 71 (1953).

17. K. L. Hoy, J. Paint Technol., 42, 76 (1970).

18. S. Sasaki, Y. Takahashi and H. Tadokoro, J. Polym. Sci., Polym. Phys. Ed., 10, 2362 (1972).

19. N. A. Pravikova, Y. B. Berman, Y. B. Lyudvig, and A. G. Davtyan, Polym. Sci. USSR (Engl. Transl.), 12, 658 (1970).

20. T. A. Orofino and P. J. Flory, J. Chem. Phys., 26, 1067 (1957).

21. D. McIntyre, A. Wims, L. C. Williams, and L. Mandelkern, J. Phys. Chem., 66, 1932 (1962).

22. W. H. Stockmayer and M. Fixman, J. Polym. Sci., C, 1, 137 (1963). 